\title{
Biological and Anthropological Foundations of Arnold Gehlen's Political Theory
}

\begin{abstract}
The problem of the body-soul separation has long been the subject of both philosophy and science. There is no doubt that man is a biological being. What is not certain is how human biology influences our actions and decision processes. Does it constitute humanity or is it just an excess. At the beginning of the twentieth century, Arnold Gehlen, who laid the foundations of the institutional theory, stated that man is a being marked by a deficiency. This statement was derived precisely from man's biological deficiencies. At the same time, those influenced the human's ability to create complex institutional systems. From the biological foundations of the analysis of man as a psychophysical being, Gehlen derived the need to establish a system of rules and norms that helps us to survive. This article will primarily discuss the biological foundations of Gehlen's theory. It will show how this $20^{\text {th }}$ century anthropologist moved from researching the biological aspects of individuals to the cultural challenges faced by modern humans.
\end{abstract}

Keywords: political anthropology, philosophical anthropology, Mängelwesen, Arnold Gehlen, language origin, institution theory

\section{Introduction}

Man is a biological being. This statement does not raise any doubts until we start to wonder to what extent human biology defines its being. Are the structure of the human body and its physiology precisely those aspects that place us in some opposition to the rest of the animal kingdom? Or, on the contrary, what distinguishes us is a certain spiritual or cultural addition. The answers to these questions are connected in time with the first attempts to solve the problem of human identity in general. Already Aristotle distinguished the body, that is, the biological-sensory state of men, from soul. Even within the human's soul, he 
distinguished individual powers. Although he endowed animals with soul, the power of reason has been assigned only to man (cf. Aristotle, 2016 [c. 350 B.C.E.]). Many centuries later, somehow defining a new paradigm in thinking about the separation of the soul from the body, Descartes presents his dissertation on seeking truth in science. He points out that what allows us to define us as humans is not corporeality, but soul and ability to think reasonably (cf. Descartes, 2004 [1637]). The dualism he presented was the basis for considering the issue of "humanity" for a long time. However, the Cartesian breakthrough did not end the discussion on the role of biology in social sciences and philosophy. Along with the development of specific sciences: sociology, psychology or political science, the question of human physicality returns, although often as one of the aspects, not the main point of reflection on man. The domination of empiricism at the end of the 19th century somehow forces an interest in human biology, not only within natural sciences, but also in the humanities, or in philosophy itself. Swiss zoologist Adolf Portmann suggests the influence of human physiology on the cultural ability of man to create developed social forms (cf. Portmann, 1969). Eventually, at the end of the 19th-century, a field emerges in which the need for a holistic view of man is re-identified. Anthropology, or literally the science of man (Greek: anthropos - human, logos - science) is a field of science where biological context of human existence is combined with his socio-cultural environment and spiritual element. It allows referring to the research results of detailed sciences, presenting the image of man "in general" and not his specific version, flattened by one aspect. It is characterized by theoretical inspirations in biological and psychological sciences. The philosophical reflection is confronted with the achievements of specific sciences (Czerniak, 2016, p. 142). The most famous representatives of classical anthropology are 20th-century researchers: Max Scheler, Helmuth Plessner and Arnold Gehlen. Each of them individually built the theoretical foundations of anthropological thinking, presenting their vision of the individual in the social reality. Out of the three, it was Gehlen who transformed his research on the biological characteristics of man into a coherent political theory. His research presents a complex theory of institutions aimed at explaining contemporary social phenomena that Gehlen as a researcher observed in the realities of 20th-century Germany. At the same time, his theory is extraordinary, as it derives primarily from the biological foundations of the analysis of man as a psychophysical being who, precisely because of certain specific biological features, was able to build the social environment, as we know it. This article will primarily discuss the biological foundations of Gehlen's theory and how Gehlen shifted from examining the physical aspects of individuals to the cultural challenges faced by modern humans. 


\section{Deficient being}

Born in 1904 in Leipzig, Gehlen deepened his knowledge in the field of biological sciences at all stages of his education. In addition to his philosophy, psychology, art history and German philology studies, he also attended classes in zoology (Witteriede, 2009, p. 95). Moreover, the promotor of his doctoral dissertation was Hans Driesch - a famous biologist and philosopher. One of the most famous works of Gehlen - Man. His Nature and Place in the World (Der Mensch, seine Natur und seine Stellung in der Welt) is a comprehensive analysis of human physicality with an opposition to the natural environment. In this book, Gehlen presents the theory of Mängelwesen, that is, a man marked by a deficiency. It is a key concept for Gehlen's anthropology, which over time has become the thinker's trademark, despite the fact that historically it was used before (The authorship of this term is attributed to Johann Gottfried Herder, cf. Herder, 2002 [1772]). Introducing his concept of man as "deficient being", Gehlen presents a simple definition: "From a biological point of view, in comparison to animals, the structure of the human body appears to be a paradox and stands out sharply" (Gehlen, 1988, p. 13). This is, of course, a simplified observation of human morphology that the author of Der Mensch deepens later in his book. He describes human organs, in comparison with animals, as "primitive" in the sense of being unspecialized. This means that in most animal cases, their individual physical features have their final form - i.e. the form that is the most adapted to surviving in the natural environment. In this case, human being is for Gehlen "not yet determined" as Nietzsche used to say. Anthropologist seeks traces of unspecialized human organs mainly in the skull and human teeth (Gehlen, 1988, p. 81). Unlike animals (including anthropoids, where the nose has developed significantly, often at the expense of the brain), in humans nose has remained in the primitive phase. Although the shape of the skull is similar in both human and anthropoid embryonic and infancy stages, after adulthood, the nasal part is fully developed only in humanoids. The same situation appears in case of teeth, which, for example, in great apes are much wider, making the jaws of these animals much more massive. Moreover, in human teeth, canine and premolars are not separated which prevents the formation of powerful animal fangs. The thinker refers here to the German anatomist Hermann Klaatsch, who, while examining humans, stated that, the condition of the man's teeth do not indicate any adaptation to survival in the natural environment (Gehlen, 1988, p. 84). Bringing together individual observations and studies, Gehlen highlights one in particular - the retardation theory (German: Retardation) of the Danish anatomist Louis Bolk (Verhulst, 1993, pp. 100-114). Bolk, in his research on human morphology, discovered that man is to some extent an exception in the animal world. Observing the various stages of human development, he stated that his development had been delayed and retarded, i.e. reached 
a level of a certain fetalization. Compared to the animal world, man is the only animal that exhibits an extremely slow growth and emergence from childhood. Individual parts of the human body, in the face of their animal counterparts, seem to be at the beginning of the development path. A problem for humans in the context of survival in the environment is also its mismatch. Animals occupy a specific place in the world, they have a habitat, and it is through their specialized organs that one can determine in what conditions they will have the best possibility to survive. On the one hand, this "binds" animals to a specific geographical area, but on the other hand ensures their survival. A man against this background is not distinguished by special qualities. His place in the world is unique. Gehlen describes it as Sonderstellung, that is, a special place of man, which significantly distinguishes him from the animal world. In fact, it is a common theme that appears also among other classics of philosophical and political anthropology. Helmuth Plessner mentions the eccentric positionality of man (Exzentrische Positionalität, cf. Plessner, 1931), and Max Scheler humans' openness to the world (Weltoffenheit, cf. Scheler, 2009).

Analysing the research of famous scientists and anatomists, Gehlen reaches unusual conclusions about the place of man within the theory of evolution. The author of Der Mensch assumes that a specialized (animal) organ cannot undergo unspecialization again in the evolution course, as is the case with man. Therefore, the evolutionary path of development for humans had to be unique in some way, and based on the theory of specialization, it is difficult to draw a straight line between humanoid and man. For the researcher, this means that man is a special "project" of nature along with his non-specialized organs: "Nature has accorded a special position to man (...) in man she has pursued a unique, hitherto untrodden path of development" (Gehlen, 1988, p. 10). The consequences of this decision will later become the basis of Gehlen's political theory. The initial main points of the Mängelwesen theory are quite pessimistic. We receive a vision of man being born as a defective individual, full of deficiencies, unspecialized and even primitive in the context of physiology. Man's special place in the world, even if unique, is a rather gloomy joke of nature. Judging this from the perspective of the most basic goal of each species - survival - humans are in a lost position. However, despite the anthropological pessimism, Gehlen's theory is far from declaring man a "loser" in the natural world. Man is forced to compensate for his lack of specialization and he does it in a way that no animal can match him - by acting. 


\section{Action and Instinct}

Speaking of human deficiencies, Gehlen at one point abandons the analysis of the structure of the human body, in favour of a topic that is much less tangible from the perspective of biology, i.e. instincts. Trying to examine the subject in a comprehensive manner, he decides to present the so-called psychology of instincts (Triebpsychologie). On the one hand, the topic of instincts could be confined to a simple definition. Theoretically, each time human organs function properly and automatically, we can talk about instinctive behaviour. Certain ways of moving, gestures or reflexes that accompany us from infancy certainly have their instinctive background. However, by analysing these behaviours more deeply, we can see that in many cases human behaviour, without a cultural context, is not so understandable when compared to animals. The plasticity of human instincts and their susceptibility to social conditions is something unheard of in the natural environment. For this reason, even in primitive societies, there are man-made laws, recommendations and prohibitions that artificially promote certain behaviours while eliminating others. They are established culturally, not biologically. Gehlen states that every concrete human behaviour " $X$ " is socially conditioned and it is a part of a system in the context of a culture (Gehlen, 1988, p. 324). The author of Die Seele im technischen Zeitalter describes this situation as a reduction of man's instincts (Instinktreduktion). Behaviour, which in colloquial speech we define as "instinctive", manifests itself rather when human is exposed to harsh and extreme conditions, forcing him to fight for life. What is more, they only work because physical deficiencies in that kind of situations such as hunger and thirst impair cognition.

The reduction of instincts, as well as physical deficiencies, in the situation of dealing with nature, puts man at a disadvantage. This leads to a situation where people feel "chronic pressure" (Gehlen, 1988, p. 352). Nature exposes all beings to certain stimuli and expects a response. Strong animal instincts meet these requirements and "provide an answer" in the form of an appropriate reaction or behaviour. Weak, malleable human instincts only lead to confusion and pressure to do something, with no indication of what. The so-called Reizuberflutung, that is, the flood of stimuli is the greatest challenge that a human being has to face. Gehlen's student, Karl-Siegbert Rehberg states that Gehlen's man lost his animal instinctive certainty (Rehberg, 2012, p. 124). This loss forces man to compensate. He cannot use his physical qualities. However, the flood of stimuli forces man to react and to act.

Handlung, or action, is a concept, which, in Gehlen's anthropology, becomes the basic tool of survival. This category goes far beyond the physical acts of movement or the satisfaction of primal needs. For the anthropologist, human action is, above all, a way to distance himself from a hostile environment. Through the act of acting and creating, man moves away from the flood of stimuli or from 
the physical aspects of the world to which he is unable to oppose his physicality. Action can be tool making, logical thinking, or planning. The animal, guided by instincts, does not feel the need to "escape" the world. Man feels it constantly, so he must change the world according to his expectations. The animal, feeling confident, closes its life in a cyclical survival mode. In order to survive, a man must break out of this circle. Rehberg states that with Gehlen, any human action can turn into a habit imbued with inner values (Rehberg, 2004, p. XIII). This means that when a person undertakes an action, he not only forecasts its immediate but also long-term consequences. What is extraordinary, in the case of a human being, the final functionality of a given tool or product may be far from the assumed original purpose. Despite this, man is able to develop it further, according to his needs.

Tool making is one of the most empirical evidence for human activity distinct from animal one. Gehlen, while studying the cultures of primitive peoples, was particularly interested in the issue of manufacturing primal tools as the first human acts of distancing from the environment. Of course, an occasional use of objects as a means does occur with anthropoids too - states Gehlen - but the advanced production of those is limited strictly to humans. When we, as researchers, are reaching the point where we can no longer tell that some deformations of nature are intentional, the history of human development is no longer within our grasp. The thinker notes that when humans make tools, the original purpose for the tool can change. Man experiments and discovers. He just does not see what is but also what he wants to see. In a piece of wood, he sees potential not only realistic (a stick for a fire), but also imaginary (a ship). For an anthropologist, toolmaking is therefore an evidence of man ability to create a new reality. Yet it is still a physical and direct action, despite its potential. Meanwhile, the category of acting as Handlung goes beyond the realm of human physicality. Man is a psychophysical and spiritual construct, so his action also does not take only a physical dimension.

Language, for Gehlen, is another part of human nature and Handlung. He presents it as one of the inimitable human characteristics. Language perfectly mediates contact with the world, and elevates the view of reality to a level unavailable to animals. Symbols, suggestions, feelings - everything that cannot always be shown can be conveyed. No animal is comparable to humans in this type of communication. While in the animal world we also observe acts of communication, it is hard for us to say that they contain something beyond the direct transmission of feelings and impressions about events in the present world. $\mathrm{Hu}-$ man language carries symbolism and is largely based on abstract communication - creating and talking about constructs that may not even exist.

Language is yet another way to distance yourself from the environment. We no longer have to perform the physical act of pointing out a thing, we can just tell about it. Gehlen presents language as one of the first tools to relieve us from 
the flood of stimuli. He states that thanks to language it is possible to limit the vastness of reality in symbols. One can communicate its behaviour and intentions without the need for direct interference and changing reality. People are able to talk about things that do not exist, that are intentions, plans, or fantasies, not even intended to be realized. Gehlen describes man at this point as a Promethean being, that is, one who can plan and act simultaneously. The language allows human to be freed from its own realm of experiences and to be able to act on the based on those of others. Therefore, it is the beginning of the creation of complex social constructs, where physical and direct communication is not always possible. An interesting issue to this topic is also the reflection of the origin of language, discussed by researchers and philosophers from the earliest times. We owe the very term "origin of language" to Herder and his work Treatise on the Origin of Language from 1772 (cf. Herder, 2002 [1772]). His considerations on the role of language led him to conclude that language is a quality that confirms humanity. The animal is perfectly equipped for survival without using it. Man, on the other hand, had to invent language somehow in order to become a man. In final reflection, Herder states that man and language arose simultaneously, because without one, the other cannot exist (Schmidt, 2012, p. 7). This view is also close to Gehlen's thought. He believes that man is a special project of nature, that is, all his features and anthropological categories that he assigns to man (Mängelwesen, Weltoffenheit, Handlung, and Reizüberflutung) are unique only to humans not animals.

For the theory of institutions' author, Handlung is the first step separating man from a hostile environment and allowing him survival. Redirecting of man's drive amounts is, after all, Mängelwesen's number one job. The stimuli, without proper processing, ultimately become unbearable for a man with poor instincts. Hunger, cold, sense of danger, lack of natural environmental orientation - all these circumstances block the ability to think efficiently. The animal, thanks to its instincts, reacts and finds its paths in this world. Man needs a plan. Gehlen repeats after Hobbes that even future hunger makes man hungry (Gehlen, 2004a, p. 56). Acting allows planning, which enables creating more durable forms ultimately resulting in the institutional order, as we know it.

\section{Institutional relief}

While publishing Gehlen's collected works in 2014, Rehberg stated that Gehlen's philosophical deliberations always had a sociological and anthropological basis (Rehberg, 2004, p. IX). Moreover, the "biologism" of the thinker's theory has often been taken as an objection and the inept reduction of the differences between man and animal to some major biological aspects (critical notes by Theodor 
Litt, cf. Jansen, 1975, p. 7). However, for the anthropologist, biology was the starting point, an empirical element, without which the foundation of his theory could only turn out to be abstract considerations. Gehlen wanted to avoid the need for a hard separation between the spirit and the body, as Descartes once proposed. For the Der Mensch author, man is a construct so complex that his physicality is intertwined with mental and spiritual issues. Hence, for Gehlen, creating separate anthropological categories became a way to approximate the complexity of man. Mängelwesen cannot be reduced to mere physical shortages, and Handlung is not only a direct action. These categories were intended to show the complexity of people, which stems from both their biological qualities and their spiritual experiences. Therefore, to understand the foundations of Gehlen's political theory, one should also familiarize himself with the above-mentioned categories. Only then, Gehlen's attachment to institutions and their praise in his theory can be understood.

Gehlen's political theory is primarily a theory of institutions. The philosopher presents the anthropological features of man to prove the necessity of the existence of strong institutions. He indicates that the most primal and fundamental feature of an institution it its capacity to provide a relief (German: Entlastung). Man, feels overload because of the aforementioned flood of stimuli. He is unable to answer them, nor can he constantly direct his attention to them. For this reason, he is looking for a way to relieve the burden permanently. The described methods of acting (language, tool making) pave the way for him to navigate more effectively in a hostile environment, but do not provide permanent results. Therefore, man has to give up some of the decision-making freedom and hand it over to another "subject". One, which could, in the long term and effectively, take care of all the issues that are determined by instincts in animals. On the one hand, these are typically physical acts - relieving the burden of thinking about getting food, so as not to feel hungry or relieving from thinking about a shelter, to have somewhere to sleep. On the other hand, for Gehlen, the mental aspect is also important - relieving man from the feeling of insecurity, loneliness and danger. Security is one of those aspects of human existence for which people are willing to sacrifice certain freedoms. Thinkers such as Thomas Hobbes (cf. Hobbes, 2010 [1651]) or Jean Jack Rousseau (cf. Rousseau, 1984 [1755]) have already conducted research about it. Hobbes conditioned the transfer of power to Leviathan by ensuring the protection of his subordinates, and Rousseau pointed safety as the reason people gave up living in a state of nature.

However, what determines the effectiveness of relieving is not only temporary relief, from the circumstances that follow, but the systemic relief, which relieves the responsibility for the shape of the surrounding reality for a long time. It is therefore a relief that is detached from the direct stimulus. It is not only the empirical cause that is important, but also the entire symbolic structure that makes man always trust a system solution. Gehlen sees the source of earliest 
institutional forms in the primitive cultures and in the so-called totemism (Gehlen, 2004b, p. 59). On the one hand, we observe very direct acts of perspective thinking among these cultures, e.g. animal husbandry. They are aiming at satisfying basic needs, relieving the necessity of thinking of hunger, etc. However, in themselves they are still insufficient to become an "institution" in the full sense of the word. For what bears the hallmarks of an institutional order is a symbolic and spiritual "binding" of a man to a given norm in such a way that it seems natural to him, despite being a cultural surplus. An example of the original form of such a solution is totemism, i.e. the social cult of a given animal, object or plant. This cult unites the group by imposing on it desirable (totem worship) and punishable (disrespect for the symbol) behaviour. It sets taboos beyond which one must not go. It imposes planning of actions in accordance with a given totem and the ideology adopted around it. Ultimately, it introduces repetition and routine that take root in the mind of the community enough to stop questioning totem idea at some point. All of this creates a relationship that is not available on the physical level, and at the same time influences the empirical reality. Therefore, totemism is the seed of an institution. The essence of an institution that is able to guarantee a real relief is its symbolic dimension and the routinization of human behaviour aimed at a specific goal. Due to the multifactorial process by which they arise, they are also objective. An institution does not have an individual dimension, it connects a group from which it becomes independent at some point.

As Gehlen shows in his work Urmensch und Spätkultur, over time totemization began to transform into institutional forms that we know very well. Marriage, family, courts, schools, religion, bringing up children are just some aspects of our reality that we do not think about every day, and which, after all, shape our lives. Some of them take more formal forms (e.g. state institutions), others function better on a psychological level (e.g. respect for the elderly). One thing is certain - to act against them means to foster order that results from our nature. Gehlen, in the context of "rebellion" against institutions, takes a very conservative position. Each such offense is a revolution for him, and the only way to change is their natural evolution, because breaking the order always leads to victims. This is obviously due to his approach to the foundations of institutions where they are derived from human nature.

\section{Human nature and the institution}

In the theory of institutions, Gehlen places man in an environmental context. On the one hand, people are forced to function in the natural environment, on the other, they are completely unadapted to it. The biological definition of man as Mängelwesen distances man from nature, while what brings him closer to humanity is his cultural and institutional surplus, that is, everything he does to 
compensate for his natural deficiencies. Rehberg, evaluating Gehlen's anthropology, states that culture in German thinker thought is an "anthropo-biological" concept resulting from the lack of connection between man and the environment (Rehberg, 1994, p. 77). For this reason, man is by nature a cultural being. This is especially important if we look at the writer's problematic biography. There is no doubt that the development of his academic career was possible e.g. thanks to his affiliation with the NSDAP. Also during his presence at the University of Leipzig, he was a representative of the National Socialist lecturers (Rehberg, 1988, p. XXIV). However, in no way does the presented anthropology of Gehlen support the Nazi philosophy of man. It glorifies strong state institutions but human nature in Gehlen's thought makes all of us equal. Every person is a deficient being. Likewise, everyone has certain unique qualities that allow us - just like in Hobbes' theory - to get out of the hostile state of nature to create a new institutional order. Thus, the writer's biological themes are important for a twofold reason. On the one hand, they allow us to trace the path that a man had to go through to get to the place where he is now. On the other hand, they show that human nature is universal and unique only for human being. For only man could break out of the natural environment and only he could create an institutional system, with the state at the forefront. The institutional order built on this philosophy means creating a cultural environment that goes beyond the direct purpose of action and enters the spiritual, transcendental level. Although Gehlen does not leave us with a precise definition of institutions, he explains that institutions fulfil their role when the ritual activity they contain is not only aimed at simply changing some fragment of reality. An institution works when its presence is visible and, at the same time, transcendent, that is, it has a value in itself (Gehlen, 2004b, p. 16). So when we think about, for example, school as an institution, on the one hand, we see real and physical buildings, but on the other hand, we understand the centuries-old structure, which consists the need to acquire knowledge, importance of an education at a young age, the legitimacy of passing on the achievements of a generation, etc. Man is for Gehlen, both a biological and a cultural being. Culture, politics and institutional order are human nature, this is the environment in which man can function and develop freely.

When analysing Gehlen's anthropology, it is worth paying attention to a certain paradox. His political theory, upon closer analysis, is an extremely conservative view of a certain institutional order, which, under the influence of changes taking place in 20th-century Germany, began to be questioned. The outbreak of subjectivism in the post-war years, questioning certain social norms or diminishing the role of the state in its clash with an individual are all changes which, for the Urmensch und Spätkultur author, are subversive and harmful to the order developed over the centuries. At the same time, when describing institutions, Gehlen does not claim that the content of the institution is the most important feature. The most important thing is the durability of norms and their universal 
acceptability at the almost-unconscious transcendental dimension. Thus, the conservatism of Gehlen's theory is not limited to pointing to certain systemic solutions, which he considers good and unchangeable. With his theory, he points out that by questioning certain norms and institutions, we are actually questioning our own nature. It is man who transformed his biological deficiencies into a complicated institutional order. Thus, he will bear the consequences of recklessly acting against this order. Of course, one may wonder where the limit of durability and universal acceptability of a given standard is. However, what needs to be remembered from the thinker's deliberations is the fact that it is our nature, with all biological and psychological aspects, that constantly pushes us to create a world based on an institutional order.

\section{References}

Aristotle. (2016) [c. 350 B.C.E.]. "On the Soul”, trans. J.A. Smith. The Internet Classics Archive, http://classics.mit.edu/Aristotle/soul.html (accessed: 28.09.2020).

Czerniak, S. (2016). "Antropologia filozoficzna jako krytyka społeczna”. Edukacja Filozoficzna, wyd. specjalne, pp. 141-164.

Descartes, R. (2004) [1637]. A Discourse on Method, trans. J. Veitch. London: Orion Publishing Group.

Gehlen, A. (1988). Man. His Nature and Place in the World, trans. C. McMillan, K. Pillemer. New York: Columbia University Press.

Gehlen, A. (2004a). "Ekspozycja kilku problemów ducha”, trans. E. Paczkowska-Łagowska. In: S. Czerniak, J. Rolewski (eds.). Studia z filozofii niemieckiej. Toruń: Wydawnictwo Naukowe Uniwersytetu Mikołaja Kopernika.

Gehlen, A. (2004b). Urmensch und Spätkultur. Frankfurt am Main: Klostermann.

Herder, J.G. (2002) [1772]. Treatise on the Origin of Language, trans. N.N. Forster. Cambridge: Cambridge University Press.

Hobbes, T. (2010) [1651]. Leviathan: Or the Matter, Forme, and Power of a Commonwealth Ecclesiasticall and Civill. London: Yale University Press.

Jansen, P. (1975). Arnold Gehlen. Die antropologische Kategorienlehre. Bonn: Herbert Grundmann.

Plessner, H. (1931). "Macht und menschliche Natur. Ein Versuch zur Anthropologie der geschichtlichen Weltansicht". Fachschriften zur Politik und staatsbürgerlichen Erziehung, 3, Berlin: Junker und Dünnhaupt.

Portmann, A. (1969). Biologische Fragmente zu einer Lehre vom Mensch. Basel-Stuttgart: Schwabe.

Rehberg, K.-S. (1988). “Gehlen's Elementary Anthropology”. In: A. Gehlen. Man, his Nature and Place in the World. New York: Columbia University Press, p. XXIX.

Rehberg, K.-S. (1994). "Antropologia działania i teoria porządku Arnolda Gehlena", trans. D. Raczkiewicz-Karłowicz. In: B. Markiewicz (ed.). Konserwatyzm. Projekt teoretyczny. Warszawa: Polskie Towarzystwo Filozoficzne, Goethe Institut.

Rehberg, K.-S. (2004). "Vorwort”. In: A. Gehlen. Urmensch und Spätkultur, ed. K.-S. Rehberg. Frankfurt am Main: Klostermann, p. XIII. 
Rehberg, K.-S. (2012). “Arnold Gehlen”. In: T. Bedorf, A. Gelhard (eds.). Die deutsche Philosophie im 20. Jahrhundert. Darmstadt: WBG.

Rousseau, J.-J. (1984) [1755]. A Discourse on Inequality. London: Penguin Group.

Scheler, M. (2009). The Human Place in the Cosmos, transl. M. Frings. Evanston: Northwestern University Press.

Schmidt, G. (2012). “O pochodzeniu języka”. Lingua ac Communitas, 22, pp. 5-14.

Verhulst, J. (1993). "Louis Bolk Revisited II - Retardation, Hypermorphosis and Body Proportions of Humans". Medical Hypotheses, 41(2), pp. 100-114.

Witteriede, H. (2009). Eine Einführung in die Philosophische Anthropologie. Frankfurt am Main: Peter Lang. 